\title{
BUCHBESPRECHUNGEN
}

\author{
HANS BRÄKER
}

\section{Kommunismus und Weltreligionen Asiens}

Zur Religions- und Asienpolitik der Sowjetunion, Bd. I, 2: Kommunismus und Islam.

\author{
Tübingen, J. C. B. Mohr (Paul Siebeck) 1971, 456 S., Index, Bibliographie
}

Mit dieser Arbeit liegt der zweite Teil der von Hans Bräker auf mehrere Bände geplanten umfangreichen Studie über das Verhältnis des Kommunismus zu den Weltreligionen Asiens vor. Der hier zu besprechende Band ist in vier Kapitel unterteilt. Im ersten Kapitel behandelt der Autor die Probleme des modernen Islam und seiner diversen Richtungen sowie den Kampf zwischen islamischer Orthodoxie und Säkularismus in der islamischen Welt. Im zweiten Kapitel geht Bräker auf die ideengeschichtlichen Quellen des Marxismus-Leninismus ein und versucht, das in ihnen entwickelte Asien-Bild herauszuarbeiten. Bräker beginnt mit Marx und weitet seine Untersuchung aus bis auf Stalins Haltung gegenüber Asien und die heutige Rolle Asiens in der sowjetischen Außenpolitik. In diesem zweiten Kapitel spürt man viele Vorurteile des kalten Krieges, ja die gesamte Untersuchung leidet unter dem Klima des kalten Krieges, obwohl der Autor ja selbst einleitend nachdrücklich davor warnt, die Probleme des modernen Islam durch die Brille des Ost-West-Konflikts zu beurteilen. Kapitel 3 und 4 sind Fallstudien über Sinkiang und Indonesien.

Nur im ersten Kapitel ist es Bräker offensichtlich gelungen, seine These: der moderne Islam dürfe nicht in Kategorien des Ost-West-Konflikts begriffen werden, konsequent durchzuhalten. So kritisiert Bräker jene Autoren, die unterstellen, Nassers Versuch, Islam und Sozialismus miteinander zu versöhnen, sei eine Tarnung seiner kommunistischen Grundposition. Diese These wird bekanntlich in der Literatur islamischer Apologeten vertreten. Bräker zeigt, daß ein solcher Versuch schon vor Nasser von frommen Muslimen unternommen wurde und daß Nasser auf keinen Fall ein Kommunist gewesen ist. Anders lautende Argumente halten „kaum stand. Wie ... festgestellt wurde, war die Herleitung eines ,Arabischen Sozialismus' aus dem Islam keineswegs eine „Erfindung' Nassers“. (p. 30) Bräker geht noch einen Schritt weiter und betont, daß auch jene sozialistischen Kräfte in der islamischen Welt, die anders als Nasser tatsächlich vom Marxismus beeinflußt, ja sogar erklärte Marxisten sind, grundsätzlich mißverstanden würden, wenn man sie in Zusammenhang mit dem Ost-West-Konflikt brächte. Diese These illustriert er anhand des Wirkens des algerischen Marxisten Bachir Hadj-Ali, dessen Position nur aus der algerischen Situation heraus, nicht aber im Rahmen des Ost-West-Konflikts verstanden werden kann. Wie gesagt, dies macht die Stärke des Buches von Bräker aus; zugleich liegt hier aber auch seine Schwäche, denn es gelingt Bräker im gesamten Buch nicht, die religionssoziologischen Probleme der islamischen Welt immanent zu verstehen.

Die Hauptschwäche des Buches resultiert jedoch aus dem Tatbestand, daß Bräker seine Studie ausschließlich dogmengeschichtlich aufgebaut hat. Er erschöpft sich darin, Ideen islamischer Denker (die er zu „Theorien“ aufwertet) und Ideen marxistischer Autoren zu referieren. So erscheinen bei Bräker die Probleme des modernen Islam als rein geistige Probleme, die mit der Realität: den vorhandenen 
Sozialstrukturen, also den tatsächlichen Problemen der Gesellschaft nicht viel zu tun haben. Beispielsweise versucht er, das Fehlen einer Demokratie in den arabischen Ländern daraus abzuleiten, daß der Islam „seine Anhänger total bindet, und zwar sowohl hinsichtlich ihres Lebens in der Gesellschaft wie auch als Staatsbürger" (p. 21). Daß eine Demokratie wesentlich andere soziale Voraussetzungen, primär ökonomische, hat und die Religion nur ein gesellschaftliches Epiphänomen ist, leuchtet Bräker nicht ein. Auch ist es absolut problematisch, wenn Bräker die heutige Krise des Islam mit der Krise in der 'Abbasiden-Zeit gleichsetzt (pp. 24 f.), zumal die historische Situation heute eine völlig andere ist. Nicht nur die gesellschaftlichen Verhältnisse haben sich inhaltlich gewandelt, sondern mit ihnen auch der Islam. Die Probleme des modernen Islam reduziert Bräker insgesamt auf das Fehlen einer theologischen Systematik: „Der muslimischen Theologie fehlt es bis heute an einer tragenden Schicht von Systematikern, die in der Lage wäre, in der islamischen Welt eine neue Konzeption des Islams durchzusetzen, eine Konzeption, die es den Gläubigern erlauben würde, dem übernommenen Neuen zuzustimmen, ohne dadurch den Geltungsbereich der Religion einschränken zu müssen.“ (p. 24) Der französische Religionssoziologe Maxime Rodinson hat in seinem Buch „L'Islam et le capitalisme“ (Paris 1966) ${ }^{1}$ nachdrücklich davor gewarnt, Religionen als getrennt von der gesellschaftlichen Realität existierend zu betrachten; davon ausgchend betont Rodinson, daß es keinen für alle Zeiten unveränderlichen Islam gibt und gegeben l.at. Der jeweilige Gehalt der Religion ist stets im Zusammenhang mit der jeweiligen konkreten gesellschaftlichen Situation zu verstehen. Das ist ein soziologisches und kein theologisches Problem. Bräker kennt Rodinsons Buch; er zitiert Rodinson, übersieht aber dessen methodische Position.

Kurzum: Bräker untersucht die Statements islamischer Denker und vermittelt sie nicht mit den sozialen Prożessen in den islamischen Ländern. Das ist ein erheblicher Mangel. Dieser Mangel wird noch vergrößert dadurch, daß Bräker keine Kenntnisse von orientalischen Sprachen (arabisch, persisch u. a.) hat und somit die Statements islamischer Denker aus der Sekundärliteratur rezipiert. Originalliteratur kennt er also nicht. Selbst die Produkte islamischer Denker, von denen Übersetzungen in europäischen Sprachen existieren, zitiert Bräker nach Sekundärquellen, so Afghani nach Smith; die amerikanische Afghani-Übersetzung von Nikki Keddie kennt Bräker nicht ${ }^{2}$. Ebenso verfährt er mit 'Abduh, dessen „Risalat at-Tauhid“ in französischer Übersetzung vorliegt ${ }^{3}$, und mit 'Abdarraziq, dessen „al-Islam wa usul al-hukm “ ebenso ins Französische übersetzt worden ist". Auch sind ihm einige wichtige Sekundärquellen entgangen, die sich mit Fragen des modernen Islam befassen. Trotz alledem ist Bräkers Arbeit eine brauchbare Sekundärquelle, wenngleich in einem sehr beschränkten Maße. Der Autor hätte seinen Gegenstand besser eingrenzen sollen, um die Problematik gründlicher behandeln zu können.

Bassam Tibi

1 Dt. Ubers.: M. Rodinson, Islam und Kapitalismus, Frankfurt/M. 1971; cf. dazu meine Rezension in: Archiv für Rechts- und Sozialphilosophie, Bd. 59 (1973), H. 1 .

2 Nikki Keddie (ed.), An Islamic Response to Imperialismus, Political and Religious Writings of Sayyid J. ad-Din 'al-Afghani, Berkeley-Los Angelos 1968; darin auch eine Bibiliographie mit Nachweisen weiterer Ubersetzungen von Afghanis Schriften in europäische Sprachen sowie der Sekundärliteratur. In$\mathrm{zwischen}$ hat Keddie auch ihre lang angekündigte Afghani-Biographie vorgelegt: N. Keddie, Sayyid J. ad-Din 'al-Afghani, A Political Biography, Berkely-Los Angelos 1972.

3 M. 'Abdou, Rissalat al tawhid ou exposé de la religion musulmane, Paris $1925,1965^{2}$.

4 "L'Islam et les bases du pouvoir", in: Revue des Etudes Islamiques, Bd. 7 (1933). pp. 353-391, und Bd. 8 (1934), pp. 163-222. Zu Afghani, 'Abduh und 'Abdarraziq cf. auch B. Tibi, Nationalismus in der Dritten Welt am arabischen Beispiel, Frankfurt/M. 1971; dort auch eine umfangreiche Bibliographie. 